\title{
RAZÃO PÚBLICA E DISCURSO RELIGIOSO NA DEMOCRACIA: DISCUSSÕES A PARTIR DAS CRÍTICAS DE HABERMAS AO LIBERALISMO POLÍTICO DE RAWLS.
}

\section{PUBLIC REASON AND RELIGIOUS DISCOURSE IN DEMOCRACY: DISCUSSIONS FROM HABERMAS' CRITICISM ON RAWLS' POLITICAL LIBERALISM}

\author{
${ }^{1}$ Guilherme Saraiva Grava \\ ${ }^{2}$ Ana Beatriz Guimarães Passos
}

\section{RESUMO}

Considerando que o pluralismo é um grande desafio para a filosofia política contemporânea, o artigo discute as implicações das críticas de Habermas ao Liberalismo Político de Rawls, focando-se na discussão sobre o papel do discurso religioso no ambiente político. Esta análise investiga se as divergências conceituais entre os dois autores efetivamente os levam a conclusões diferentes. Assim como sugerido por Yates (2007), trabalha-se com a hipótese de que ambas as teses exigem dos postulantes de doutrinas religiosas um esforço de separação entre as suas visões de mundo e uma concepção de justiça com bases de justificação neutras.

Palavras-Chave: Razão pública; Liberalismo político; Justiça procedimental; Discurso religioso; Teorias da Justiça

\begin{abstract}
Considering that pluralism is a major challenge to contemporary political philosophy, the paper discusses the implications of Habermas' criticism on Rawls' Political Liberalism, with a focus on the issue of the role of religious discourse in the political environment. This analysis inquires if the conceptual differences between the two authors effectively lead them to different conclusions. As suggested by Yates (2007), this paper works with the hypothesis that both theses require from the postulants of religious doctrines an effort of separation between their comprehensive views and a conception of justice with neutral bases of justification.
\end{abstract}

KEYWORDS: Public reason; Political liberalism; Procedural justice; Religious discourse; Theories of Justice

\footnotetext{
${ }^{1}$ Mestrando em Direito e Desenvolvimento pela Fundação Getúlio Vargas - FGV Direito SP, São Paulo, SP, (Brasil). Bacharel em Direito pela Pontifícia Universidade Católica de São Paulo, PUC/SP, São Paulo, SP, (Brasil). E-mail: gsgrava@gmail.com.

2 Mestranda em Direito e Desenvolvimento pela Fundação Getúlio Vargas - FGV Direito SP, São Paulo, SP, (Brasil). Bacharel em Direito pela Pontifícia Universidade Católica de São Paulo, PUC/SP, São Paulo, SP, (Brasil). E-mail: anabeatrizgpassos@gmail.com.
} 


\section{INTRODUÇÃO}

A discussão sobre o papel das diversas crenças na esfera pública e na vida política constitui tema fundamental ao Liberalismo Político, cuja origem histórica remonta às guerras religiosas e às reformas protestantes no início da Idade Moderna (RAWLS, 2005, p. xxi-xxiv; HABERMAS, 2006, p. 4). Atualmente, o grande desafio assumido pelos liberais é o de lidar com o fato de que em sociedades democráticas, nas quais se preservam liberdades e igualdades, os cidadãos são inevitavelmente expostos tanto ao pluralismo de posições quanto de pensamentos céticos, morais ou filosóficos. Consequentemente, surgem "concepções de bem" conflitantes, muitas vezes responsáveis pela origem de antagonismos irreconciliáveis.

$\mathrm{Na}$ tentativa de oferecer uma concepção política de justiça que seja, ao mesmo tempo, independente de qualquer doutrina específica e situada no consenso sobreposto entre elas, o projeto apresentado por John Rawls em Political Liberalism (2005) pretende resolver os dilemas do pluralismo e da tolerância através da seguinte indagação: "como é possível que exista, ao longo do tempo, uma sociedade justa e estável de cidadãos livres e iguais profundamente dividida por doutrinas religiosas, filosóficas e morais razoáveis mas incompatíveis entre si?” (RAWLS, 2005, p. xviii e 3-4, tradução nossa).

Neste contexto, o objetivo do presente artigo é o de contrastar o Liberalismo Político de Rawls com as críticas trazidas por Jürgen Habermas nos artigos Reconciliation Through the Public Use of Reason (1995) e Religion in the Public Sphere (2006). A partir da discussão acerca das visões dos dois autores, busca-se identificar em que medida as observações de Habermas o levam a conclusões diferentes daquelas que desaprova em Rawls. Assim como sugerido por Yates (2007), trabalha-se com a hipótese de que, mesmo divergentes, ambas as teses exigem dos postulantes de doutrinas religiosas um esforço de separação entre as suas visões morais abrangentes e uma concepção política justificada através de bases neutras.

Para tratar destas questões, o artigo é dividido em três partes. Na primeira, apresentase uma breve exposição da teoria política de Rawls. Na segunda, são estudadas as críticas de Habermas e as questões de discordância entre os dois autores a respeito das bases conceituais do Liberalismo Político. Por fim, são oferecidas reflexões sobre o papel do discurso religioso nos espaços públicos de deliberação. 


\section{JUSTIÇA COMO EQUIDADE, LIBERALISMO POLÍTICO E DISCURSO RELIGIOSO NA RAZÃO PÚBLICA}

A John Rawls é atribuída a responsabilidade pelo renascimento da filosofia política normativa, a qual, até a publicação de A Theory of Justice, em 1971, encontrava-se presa entre dois extremos. De um lado, estava o Utilitarismo ${ }^{3}$, que oferecia os subsídios para uma concepção de justiça baseada no princípio da maximização da utilidade. De outro, havia aqueles que, mesmo apontando falhas em tal teoria, eram incapazes de oferecer uma alternativa sistemática e factível para superá-la (KYMLICKA, 2006, p. 11 e 64).

A proposta desenvolvida por Rawls, denominada "justiça como equidade", estruturase como uma abstração da clássica doutrina do contrato social, estabelecendo as condições de um procedimento hipotético e equitativo a partir do qual são derivados os princípios de justiça adequados a uma sociedade bem-ordenada.

No primeiro estágio deste procedimento, que Rawls chama de "posição original", representantes racionais dos cidadãos encontram-se fora da sociedade com o propósito de formular os princípios de justiça aplicáveis à sua estrutura básica, isto é, às suas principais instituições sociais e políticas, que interagem como um sistema unido de cooperação ${ }^{4}$. Nesta circunstância, mencionados agentes encontram-se cobertos por um "véu da ignorância" que os impede de distinguir gênero, etnia, habilidades físicas e intelectuais ou, ainda, condições sociais, econômicas e religiosas dos cidadãos que representam. Assim, deliberam tais princípios de maneira "absolutamente imparcial, pois, não sabendo qual sua futura inserção na sociedade que estão estruturando, irão racionalmente buscar estabelecer um ambiente que não lhes seja desfavorável” (VIEIRA, 2010, p. 235).

\footnotetext{
${ }^{3}$ O Utilitarismo foi desenvolvido no século XIX por Jeremy Bentham e John Stuart Mill. Segundo os utilitaristas, a moralidade de um ato ou de um procedimento pode ser medida de acordo com a sua capacidade de maximização da utilidade (esta última entendida, de modo geral, como uma forma de bem-estar). A concepção mais simples e difundida do Utilitarismo sugere que a melhor alternativa de ação moral é aquela que produz a maior felicidade para o maior número de pessoas. Os aspectos mais atrativos do Utilitarismo decorrem da sua capacidade de relacionar as regras morais a uma concepção intuitiva de justiça, comparando eventos a partir de suas consequências para o bem-estar dos indivíduos. Suas principais falhas, no entanto, resultam da inaptidão que tem para considerar direitos, preferências e liberdades individuais. Não há, no âmbito do Utilitarismo, limites para o sacrifício do indivíduo em prol da coletividade (KYMLICKA, 2006, p. 11, 14 e 63).

${ }^{4}$ Podem ser citadas a título de exemplo "a constituição, os procedimentos legais e processuais, a instituição da propriedade, as leis e convenções que regulam mercados, produção econômica e câmbio, e a instituição da família" (FREEMAN, 2003, p. 3, tradução nossa).
} 
Diante dessas condições restritivas, segundo Rawls, os indivíduos escolheriam dois princípios de justiça. Em primeiro lugar, procurariam resguardar um conjunto de liberdades básicas que incluem as de consciência, pensamento, associação e todas aquelas que definem a integridade, a participação política e a manutenção do império do Direito (FREEMAN, 2003, p. 4). Em segundo lugar, instituiriam um sistema de justiça distributiva que, ao mesmo tempo em que procuraria criar condições de repartição equitativa de recursos e oportunidades, evitaria “os problemas de um igualitarismo que não se beneficia dos incentivos provocados pela desigualdade" (VIEIRA, 2010, p. 236). Assim, o chamado "princípio da diferença" procuraria equilibrar as desigualdades na medida em que estas manifestar-se-iam em benefício dos menos favorecidos. O autor sistematiza, então, os dois princípios de justiça derivados da posição original, ordenando-os por meio de duas regras de prioridade léxica:

PRIMEIRO PRINCÍPIO: Cada pessoa deve ter direitos iguais ao mais extensivo sistema de liberdades básicas equitativas, compatível com o sistema de liberdades similares para todos.

SEGUNDO PRINCÍPIO: Desigualdades econômicas e sociais devem ser ordenadas de maneira que ambas: (a) produzam o maior benefício possível aos menos favorecidos, de modo consistente com o princípio da poupança justa; (b) atreladas a posições e cargos acessíveis a todos em condições equitativas de oportunidades.

PRIMEIRA REGRA DE PRIORIDADE: Os princípios de justiça devem ser ordenados de maneira léxica e, portanto, as liberdades básicas são restringidas apenas em função da própria liberdade. Existem dois casos: (a) uma liberdade menos extensiva deve fortalecer o sistema total de liberdades compartilhado por todos; (b) uma liberdade desigual deve ser aceitável àqueles com menos liberdades.

SEGUNDA REGRA DE PRIORIDADE: O segundo princípio de justiça é lexicamente anterior ao princípio da eficiência e àquele da maximização da soma de vantagens; e oportunidades equitativas são anteriores ao princípio da diferença. Existem dois casos: (a) uma desigualdade de oportunidades deve aumentar as oportunidades daqueles com menos oportunidades; (b) uma taxa 
de poupança excessiva deve, ao final, minimizar os fardos de quem os suporta (RAWLS, 1999, p. 53 e 266-267)

Depois de estabelecer o conteúdo substantivo dos princípios de justiça a partir do ponto de vista mais abstrato, Rawls passa a definir a formação do arranjo institucional que acompanha, na sequência, a elaboração da justiça como equidade, que vai tomando forma cada vez mais concreta. Nesse sentido, sugere que o "véu da ignorância" não é retirado imediatamente, mas em estágios progressivos, que envolvem a elaboração das normas constitucionais, a atividade legislativa infraconstitucional, e, por fim, a aplicação das regras a casos específicos (RAWLS, 1999, p. 171-175).

Diversos conceitos que acompanham este quadro geral da "justiça como equidade" foram modificados por Rawls ao longo das publicações que se seguiram à Teoria da Justiça. Um deles, em particular, é a ideia de uma "sociedade bem-ordenada", assim definida:

Dizer que uma sociedade é bem-ordenada implica três coisas: a primeira (implícita na ideia de uma concepção de justiça publicamente reconhecida), é a de que se trata de uma sociedade na qual cada um aceita, e sabe que todos os demais aceitam, os mesmos princípios de justiça; a segunda (implícita na ideia de uma regulação efetiva dessa concepção), é a de que a sua estrutura básica isto é, suas instituições políticas e sociais principais e como elas se encaixam como um sistema de cooperação - é publicamente reconhecida por satisfazer esses princípios, havendo, ao menos, bons motivos para assim acreditar. A terceira é a de que os cidadãos possuem um senso normalmente efetivo de justiça e, assim, geralmente agem em conformidade com as instituições básicas da sociedade, as quais consideram justas. Nesta sociedade, a concepção publicamente reconhecida de justiça estabelece um ponto de vista compartilhado a partir do qual se pode adjudicar as reivindicações sociais dos cidadãos (RAWLS, 2005, p. 35).

Rawls considera sua concepção original pouco realista para as democracias contemporâneas justamente porque um de seus aspectos principais é o de que os cidadãos reconhecem e aceitam esses princípios de justiça na base do que, mais tarde, passou a definir 
como uma "doutrina filosófica abrangente" (RAWLS, 2005, p. xvi). Nesse sentido, entendeu que não estava clara a distinção que viria a sustentar de maneira mais expressiva posteriormente, de que os princípios da justiça como equidade, aplicados à estrutura básica da sociedade, não se confundem com as outras doutrinas filosóficas, religiosas ou morais que frequentemente existem nas democracias. Caso contrário, seu modelo estaria endossando ou se estruturando a partir de uma concepção específica de mundo, o que comprometeria a sua estabilidade, já que estas visões sustentadas pelos cidadãos em sociedades livres e plurais não apenas são diferentes, mas são, por vezes, incompatíveis e irreconciliáveis.

O desafio, então, é o de trabalhar com uma concepção de justiça que possa combinar os seguintes elementos: (a) aplicar-se de modo generalizado à estrutura básica da sociedade; (b) servir de guia para os direitos e para as obrigações de tal estrutura; (c) ser elaborada de forma que todos os cidadãos, livres e iguais, possam endossá-la sem prejuízo das suas visões particulares de mundo (denominadas “doutrinas morais abrangentes").

Rawls aponta o Liberalismo Político como uma alternativa viável, já que configura uma doutrina restrita ao domínio do político. Nessa nova visão, os princípios de justiça produzidos a partir da posição original deveriam estar atrelados a uma concepção política de justiça, que se sustenta livremente em suas próprias bases de justificação (Rawls a caracteriza como freestanding ou autossustentada).

Uma definição de justiça como esta, portanto, é aquela que: (a) limita-se a estabelecer as diretrizes para os arranjos das instituições sociais e políticas da estrutura básica da sociedade; (b) independe de qualquer visão de mundo religiosa, filosófica ou moral e (c) compõe-se apenas por ideias políticas, não postulando sobre questões alheias a este domínio (RAWLS, 2005, p. 374-375).

A partir dessa releitura, são estabelecidas as premissas de Political Liberalism (2005), invertendo a visão tradicional de que o conteúdo da filosofia política deveria ser originado de uma concepção moral mais ampla:

Eu penso no liberalismo político como uma doutrina que se insere na categoria do político. Ela trabalha inteiramente naquele domínio e não depende de nada externo a ele. A visão mais familiar da filosofia política é a de que conceitos, princípios, ideais e outros elementos são apresentados como consequências de doutrinas abrangentes - religiosas, metafísicas e morais. Em contraste, a 
filosofia política, como entendida pelo liberalismo político, consiste amplamente de diferentes concepções políticas de direito e de justiça que são vistos de forma autossustentada [freestanding] [...]

Penso na justiça como equidade desenvolvendo uma concepção política e liberal de justiça para um regime democrático: uma que pode ser aceita - ou ao menos esperada - por todas as doutrinas abrangentes razoáveis que existem em uma democracia regulada por ela ou por outra visão similar (RAWLS, 2005, p. 374-375, tradução nossa).

Rawls oferece, portanto, uma concepção dualista, que separa a justiça política em seu campo de atuação próprio, “deixando o restante da filosofia como está" (RAWLS, 2005, p. 375). Entende, assim, que a justiça como equidade pode se situar no foco de um consenso sobreposto entre as diversas doutrinas morais abrangentes, firmando-se em suas próprias bases de justificação (freestading), sem depender, endossar ou afastar visões externas.

Nesse sentido, como o Liberalismo Político procura incorporar distintas visões morais abrangentes, situando os princípios que ordenam a estrutura básica da sociedade no foco de um consenso sobreposto entre elas, Rawls considera que as decisões políticas essenciais devem ser elaboradas e sustentadas a partir de uma racionalidade exclusivamente política. Afinal, os acordos dessa natureza não poderiam ser alcançados somente a partir das visões de mundo específicas de cada cidadão, uma vez que as doutrinas morais são diferentes e potencialmente incompatíveis entre si. Portanto, o espaço público de deliberação torna-se um ambiente discursivo idealizado, no qual são aceitos apenas os tipos de razões que os cidadãos podem oferecer entre si em termos razoáveis e aceitáveis reciprocamente por todos. A essa racionalização, cujo conteúdo é informado pelos princípios da concepção da justiça política, Rawls denomina "razão pública" (RAWLS, 2005).

Este ambiente idealizado da razão pública, restrito à categoria do político, orienta-se por um princípio liberal de legitimidade que impõe a todos os cidadãos um dever moral de civilidade e de reciprocidade. Isso significa dizer que o exercício do poder político é legítimo quando observa os fundamentos dos princípios de justiça política. Assim, da mesma forma que não se pode esperar que alguém abdique de sua doutrina religiosa, moral ou filosófica para 
tomar parte do espaço público de deliberação, também não se pode nele aceitar a presença de elementos de qualquer concepção abrangente que se sobreponham às demais:

[...] nosso exercício do poder político [no liberalismo político] é adequado e, assim, justificável, apenas quando é exercido de acordo com uma constituição cujos fundamentos podem ser razoavelmente endossados por todos os cidadãos à luz de princípios e ideais que podem ser aceitos por eles como seres razoáveis e racionais. Este é o princípio liberal de legitimidade. E uma vez que o exercício do poder político deve ele próprio ser legítimo, o ideal de cidadania impõe um dever moral, não jurídico - o dever da civilidade - que é o de ser capaz de oferecer explicações aos outros indivíduos sobre o modo como os princípios e políticas defendidos e nos quais se vota podem ser sustentados por valores políticos da razão pública. Esse dever também evolve a disposição de ouvir aos demais e a sinceridade [fairmindedness] na decisão sobre quando acomodações para conciliar os pontos de vista deveriam ser realizadas (RAWLS, 2005, p. 217, tradução nossa).

Em síntese, foram evidenciados, nesta seção, os seguintes aspectos da justiça como equidade e do Liberalismo Político de Rawls: (a) as principais instituições da sociedade - sua estrutura básica - são reguladas por princípios de justiça substantivos; (b) tais princípios são derivados de um modelo procedimental, dividido em etapas, sendo a primeira delas a "posição original"; (c) os princípios de justiça e os fundamentos constitucionais derivados desse procedimento são balizados por uma concepção política de justiça; (d) esta última caracterizase por ser autossustentada [freestanding] e por estar situada no consenso sobreposto das várias doutrinas morais abrangentes; (e) os espaços de deliberação política são orientados pela razão pública, com seu princípio liberal de legitimidade e deveres de civilidade e reciprocidade.

Apresentam-se, a seguir, algumas das críticas de Habermas às teses de Rawls. Buscase indicar, com isso, os fundamentos das discordâncias que levam os dois autores a posições diferentes sobre a participação do discurso religioso na razão pública, tema discutido na quarta seção deste artigo 


\section{OBJEÇÕES DE HABERMAS AO LIBERALISMO POLÍtico E AS RESPOSTAS OFERECIDAS POR RAWLS}

O filósofo alemão Jürgen Habermas é considerado um dos maiores expoentes da segunda geração da Escola de Frankfurt, tendo elaborado uma vasta produção acadêmica. Conhecido por seus conceitos de "ação comunicativa", "ética discursiva" e "esfera pública", Habermas compartilha uma posição semelhante ao Liberalismo Político de Rawls ${ }^{5}$.

Segundo o autor, a legitimidade das leis é garantida através de bases públicas de deliberação orientadas pelo que denomina "princípio discursivo", isto é, as normas são legítimas "na medida em que todos aqueles possivelmente afetados possam aceitá-las como participantes de um discurso racional" (YATES, 2007, p. 881). Entretanto, Habermas é crítico às teses de Rawls, discorrendo sobre elas no artigo Reconciliation Through the Public Use of Reason: Remarks on John Rawls's Political Liberalism (1995).

Primeiramente, apresenta críticas à posição original, mecanismo que, a seu ver, não obtém sucesso em estabelecer um acordo equitativo capaz de elaborar princípios substantivos de justiça. Na concepção de Habermas, a operacionalização do ponto de vista moral dos representantes dos cidadãos apresenta três consequências indesejadas (1995, p. 112):

(a) Se estes representantes agem egoisticamente a partir da sua capacidade de conceber o bem (racionalidade), jamais poderiam compreender verdadeiramente os interesses dos cidadãos que representam. Assim, a descrição de Rawls não sustentaria, de forma consistente, o modo pelo qual indivíduos plenamente autônomos poderiam ser representados por outros carecedores de uma autonomia plena. Assim, se exige destes últimos o fardo de levar a sério, no momento da formulação dos princípios de justiça, implicações e consequências de uma autonomia que não detêm.

\footnotetext{
${ }^{5}$ Habermas e Rawls assemelham-se ao apresentar teorias de justiça não-metafísicas, que procedimentalizam a razão prática kantiana. No entanto, ainda que de um modo geral compartilhem de um objetivo comum, suas posições são frequentemente debatidas na literatura a partir de suas diferenças e não de suas semelhanças (talvez porque ambos os autores produziram trabalhos em que criticam diretamente um ao outro). Como ressaltado na introdução, este artigo discute, na seção seguinte, a extensão destas diferenças e semelhanças a partir do tema do discurso religioso no ambiente político. Esta seção, por sua vez, introduz o debate a partir de divergências mais gerais.
} 
(b) Como as partes situadas na posição original não podem compreender a noção de “direitos”, os direitos básicos dos cidadãos são assimilados a bens primários. Tais limitações forçam Rawls a construir sua concepção sobre as liberdades básicas a partir da concepção de direitos básicos, ao passo que estes são equiparados a bens primários, o que torna obscura a relevante distinção entre direitos e bens. Como Rawls objetiva preservar a intuição deontológica expressa nestas distinções, acaba por ser obrigado a estabelecer uma prioridade léxica do princípio da liberdade sobre o princípio da diferença, fato que dificilmente se sustenta sem contradizer a equiparação anterior.

(c) Estas falhas comprometem a verdadeira imparcialidade no julgamento através da posição original. Ao imaginar uma situação hipotética em que os representantes dos cidadãos encontram-se em condições equitativas, Rawls busca procedimentalizar o imperativo categórico ${ }^{6}$, fornecendo o conteúdo substantivo dos seus princípios de justiça. Contudo, para realizar esta tarefa, assume um ônus que não consegue superar, justamente porque pretende limitar, desde o início, o ponto de vista moral das partes.

Em segundo lugar, Habermas sugere que a teoria de Rawls possui deficiências de justificação, pois os princípios elaborados a partir da posição original não decorrem apenas do processo de deliberação entre os representantes dos cidadãos, mas também das intuições e dos conceitos que orientam o desenho do mecanismo de representação. Nesse sentido, não apenas a posição original acaba por depender de prévias intuições e de conceitos que necessitam de justificação, mas também a própria ideia de um consenso sobreposto de doutrinas morais abrangentes não é suficiente para confirmar a correição da teoria de Rawls ou mesmo a sua estabilidade (1995, p. 119-131).

Buscando demonstrar a aceitabilidade da sua concepção de justiça pelas diversas doutrinas morais abrangentes, Rawls indica duas etapas de justificação: a primeira corresponde à posição original, quando os princípios de justiça são elaborados sob o véu da ignorância. Nela, pretende estabelecer bases conceituais que sejam neutras, reconstruindo intuições encontradas em sociedades democráticas até chegar a um “equilíbrio reflexivo”. Na segunda

\footnotetext{
${ }^{6}$ Em A Theory of Justice, Rawls reconhece que a posição original pode ser interpretada como uma procedimentalização da autonomia kantiana, pois o véu da ignorância imposto aos representantes dos cidadãos pretende estabelecer as condições para que os princípios de justiça sejam escolhidos sem a interferência de contingências naturais ou sociais (RAWLS, 1999, p. 221-227).
} 
etapa, correspondente à razão pública, momento em que os princípios já estão institucionalizados, apresenta a justiça como equidade situada no foco de um consenso sobreposto de doutrinas morais abrangentes, o que ocorre quando os princípios de justiça são expostos à discussão pública.

De acordo com Habermas, a construção destas duas etapas de justificação é problemática porque o teste de aceitabilidade deixa de ser demonstrado apenas no plano abstrato e passa a ser postergado à prática de "cidadãos de carne e osso". Desse modo, o consenso encontrado somente expressa uma possível contribuição da teoria da justiça à institucionalização da cooperação social, ao passo que a sua justificação teórica é, na verdade, pressuposta, tornando-se obscura a distinção entre a aceitabilidade e a aceitação.

$\mathrm{Na}$ sequência, Habermas descreve sua terceira crítica como resultante das duas primeiras. Isso porque, compreende que o desenho da posição original e a assimilação de questões de validade e de aceitação apontam em um mesmo sentido: Rawls permanece dependente de presunções normativas substantivas ao mesmo tempo em que pretende formular uma teoria universalista da justiça, conectada a questões de estabilidade através de um consenso sobreposto. No entender de Habermas, isso compromete seu status epistêmico (1995, p. 126-131).

De acordo com a sua interpretação, o caráter bifásico da justiça como equidade (nas duas etapas de justificação) acarreta outra consequência indesejada ao projeto de Rawls, pois a atuação dos cidadãos deixa de ser efetivamente autônoma. Isso ocorre porque os princípios básicos e a Constituição (que determinam o conteúdo da razão pública) seriam elementos indisponíveis à sua ingerência. Consequentemente, tem-se o enfraquecimento do processo democrático, colocando-se em conflito o sistema de liberdades básicas e públicas.

Diante destas três ressalvas principais, Habermas propõe a elaboração de uma teoria da justiça procedimental, que não objetiva a construção de princípios substantivos de maneira semelhante à justiça como equidade, mas que, em seu lugar, oferece as condições ideais e racionais necessárias para que os cidadãos livres e iguais possam, em um ambiente político de discussões, estabelecer a sua coexistência a partir de um direito positivo legítimo.

Para Habermas, o melhor critério de diferenciação do político é o da regulação legal (ou jurídica), uma vez que é por meio do direito positivo e coercitivo que a vida da comunidade política é legitimamente regulada. Dessa maneira, não existiria embate entre a autonomia 
pública e privada, já que os cidadãos seriam politicamente autônomos apenas quando pudessem considerar a si mesmos autores de leis às quais deveriam sujeitar-se.

Trata-se, portanto, de uma reconstrução da ideia de razão prática: ao invés de oferecer um procedimento que permite a formulação de máximas universais dedutíveis da racionalidade individual, propõe uma "quase-transcendentalização" da consciência através da submissão de referidas máximas ao discurso racional praticado pela comunidade (HABERMAS, 1995, p. 117).

A ênfase deixa de ser no que cada um poderia desejar sem contradições, passando àquilo que todos conseguem aceitar mediante o discurso racional. Nesse sentido, o mecanismo de representação concebido na teoria da ética discursiva de Habermas, isto é, o "discurso racional", teria a vantagem de evitar as dificuldades enfrentadas por Rawls. Ao invés de imaginar um pacto fictício entre partes idealizadas, apresenta a concepção de um procedimento de argumentação prática capaz de viabilizar acordos racionais dos sujeitos aos quais as normas se aplicam a partir do exercício da empatia, em que cada indivíduo assume, hipoteticamente, o papel dos demais (HABERMAS, 1995, p. 118-119).

Por fim, ainda que os autores compartilhem de um entendimento procedimental da razão prática kantiana, sugerindo uma concepção não-metafísica de justiça que se sustenta em bases autônomas (FORST, 2012, p. 78-82), as proposições se afastam na medida em que atendem a objetivos distintos. Para Rawls, o ideal de justiça encontra-se atrelado aos princípios substantivos que ordenam o arranjo das instituições essenciais de uma sociedade, isto é, a sua “estrutura básica". Habermas, por sua vez, interpreta o termo como uma dimensão normativa de validade, que não possui elementos valorativos ou materiais (GLEDHILL, 2011, p. 181).

Em função dessas diferenças, ambos divergem a respeito dos tipos de razões que podem ou não fazer parte do espaço público de deliberação e justificação em sociedades plurais, marcadas pela presença de cidadãos (livres e iguais) com visões de mundo divergentes a respeito de temas filosóficos, morais ou religiosos. Na quarta e última seção deste artigo são apresentadas algumas reflexões sobre a implicação dessas discordâncias na posição dos autores sobre o papel das religiões no espaço público de deliberação.

\section{RAZÃo PÚblica E O PAPEL DO DISCURSO RELIGIOSO NO LIBERALISMO POLÍTICO}


A partir das divergências analisadas na seção anterior, os autores estudados sustentam concepções diferentes a respeito dos tipos de razões que podem ser aceitos nos espaços de deliberação em democracias plurais. Esta seção discute a extensão destas divergências e as suas possíveis semelhanças.

De acordo com Rawls, no âmbito da razão pública, o debate de questões políticas fundamentais permite tão somente o apelo a concepções políticas. Conceitos provenientes de doutrinas religiosas, filosóficas ou morais abrangentes somente podem ser introduzidos à razão pública uma vez que apresentem, em seu devido tempo, fundamentos políticos aptos a suportálos. Através deste procedimento, denominado por Rawls de proviso ${ }^{7}$, exige-se do indivíduo religioso que encontre razões políticas para participar das discussões públicas. São essas as bases do princípio liberal de legitimidade e dos deveres de civilidade e de reciprocidade que os cidadãos, livres e iguais, devem uns aos outros.

Em Religion in the Public Sphere (2006), Habermas expressa sua discordância em relação a esta visão de Rawls porque entende que ela implica um fardo cognitivo injusto aos seguidores de crenças religiosas, que não possuem, muitas vezes, condições de conduzir esta separação entre as razões públicas e privadas demandadas por Rawls. Segundo Habermas, enquanto se espera de alguns uma verdadeira bipartição de sua identidade, o Estado acaba por privilegiar visões céticas. Isso seria um contrassenso para as pretensões do liberalismo, que justamente se propõem a lidar com a pluralidade de valores a partir de bases neutras de deliberação e justificação, privilegiando todas as doutrinas razoáveis de modo equitativo.

Diante dessas divergências, um primeiro aspecto a ser destacado é o de que os deveres de reciprocidade e de civilidade estabelecidos por Rawls na sua concepção da razão pública decorrem especificamente da maneira pela qual concebe a justiça política em bases autossustentadas, o que remete não apenas à suficiência de suas próprias razões, mas também ao consenso sobreposto de doutrinas morais abrangentes que a legitimam.

Habermas, de sua parte, não pretende estabelecer estas mesmas exigências e não diferencia, desde o início, e a partir de princípios substantivos, um conteúdo material específico para a esfera pública. Na verdade, sua crítica o leva a concluir que os problemas encontrados por Rawls na formulação desses princípios próprios da justiça política poderiam ser resolvidos

\footnotetext{
${ }^{7}$ O proviso é apresentado em The Idea of Public Reason Revisited (RAWLS, 2005, p. 453 e 462-466).
} 
através da elaboração de uma teoria procedimental como a sua. Oferece, assim, uma concepção de autonomia política a partir das formas normativas de regulação jurídica.

Nesse sentido, enquanto o liberalismo de Rawls implica o reconhecimento de um papel restrito das religiões (e de outras doutrinas morais abrangentes, incluindo-se as céticas) no uso público da razão, a ética discursiva de Habermas não vê motivos para afastar, a priori, quaisquer argumentos da esfera pública. Na verdade, como ressalta Yates, o autor reconhece que as fronteiras entre razões seculares e religiosas são fluidas, de modo que a inclusão de elementos religiosos no debate público é importante até mesmo para determinar, em um ambiente de cooperação entre os cidadãos, os limites que orientam a atividade legislativa conduzida por todos (YATES, 2007, p. 884).

Assim, tanto os religiosos quanto os céticos exercem o mesmo papel fundamental nos ambientes de debates públicos, apresentando suas posições e sustentando-as em um contexto no qual visões de mundo diferentes podem se opor. Dessa maneira, se Rawls rejeita o uso de argumentos religiosos por entender que a base pública de deliberação e justificação deve ser política (isto é, neutra), Habermas parece buscar essa imparcialidade a partir da composição do contraste de visões de mundo antagônicas.

Essas considerações levam a outro aspecto bastante relevante, relativo à diferenciação nas concepções entre a razão pública de Rawls e a esfera pública de Habermas. Como se viu, a primeira exige dos cidadãos a capacidade de afirmar suas convicções de modo sustentado exclusivamente em valores políticos. A introdução de doutrinas abrangentes na discussão política é possível, mas é necessário apresentar, no seu devido tempo, razões políticas que as suportem. Nesse sentido, discursos religiosos não podem ser amparados de maneira autônoma, devendo ser transformados em conceitos políticos adequados às exigências da justiça como equidade.

A esfera pública de Habermas, por sua vez, é estruturada de forma distinta, e pretende oferecer uma resposta ao pluralismo a partir de uma teoria procedimental que pode permanecer indiferente às diversas visões de mundo. Como carece de fundamentação em princípios substantivos, inexiste a noção de uma justiça política autossustentada. Considerando o seu objetivo de proteger todas as crenças de forma equitativa, o Estado liberal não pode exigir, segundo Habermas, que todos justifiquem suas posições políticas de maneira independente das suas convicções religiosas. Se assim fizesse, estaria violando as suas próprias pretensões de 
abrangência. Sob este ângulo, a deliberação pública em democracias constitucionais deve ser livre e diversa, o que é uma condição necessária de neutralidade.

Habermas, no entanto, reconhece uma diferença fundamental entre deliberação e justificação públicas. No primeiro campo, em que se apresentam argumentos e visões de mundo tendentes a orientar a tomada de decisões, a participação de discursos religiosos é livre. Todavia, no segundo, no qual os argumentos ganham o corpo de decisões normativas vinculantes, as convicções particulares não são suficientes. Na verdade, Habermas reconhece que deve existir um proviso institucional, no sentido de que estas decisões devem ser justificadas a partir de argumentos aceitáveis de maneira generalizada - o que se pode determinar a partir das discussões públicas orientadas pelos princípios procedimentais da ética discursiva. Existe, portanto, uma informalidade na esfera pública, justamente na qual os discursos religiosos podem aparecer como objeto de deliberação. Há, também, um aspecto formal, referente às decisões definitivas e vinculantes, que, de sua parte, precisam produzir bases de justificação que observem um princípio de neutralidade segundo o qual todas as decisões políticas são formuladas em uma linguagem igualmente acessível a todos os cidadãos (HABERMAS, 2006, p. 7-12 e MAUTNER, 2013, p. 22-24). Como se observa, Habermas não afasta por completo a noção de proviso, isto é, a obrigatoriedade de que exista um procedimento de adequação das posições religiosas a argumentos políticos.

Contudo, sua elaboração desloca o proviso a uma dimensão institucional, em que efetivamente os argumentos transformam-se em normas coercitivas. A vantagem seria de que, dessa forma, poupa-se o cidadão comum do fardo cognitivo de estabelecer, a si próprio, a separação dos papéis (ou das identidades) políticos ou religiosos, adequados, respectivamente, ao ambiente público, ou não-público. A demanda do proviso institucional recai somente sobre políticos, ministros e juízes - enfim, sobre aqueles que, em razão de sua atividade, devem permanecer neutros diante de visões de mundo distintas. Aos cidadãos basta a exigência plausível de reconhecer que a autoridade política deve ser exercida com neutralidade.

Neste cenário, resta a impressão de que, a despeito das formulações de Habermas e das críticas quanto ao fardo cognitivo imposto pela teoria de Rawls aos cidadãos religiosos, as divergências entre os autores são, na verdade, superficiais, implicando consequências muito semelhantes. Dois são os motivos que podem a sustentar essa interpretação. 
Tem-se, em primeiro lugar, que o conceito de razão pública em Rawls é, de fato, mais restrito do que a esfera pública em Habermas, o que se deve, parcialmente, à sua adstrição a uma concepção política de justiça governada por princípios substantivos. As diferenças entre as duas, no entanto, não são suficientes para que Habermas afaste por completo a exigência do proviso, ainda que possa deslocá-la a uma outra dimensão de sua teoria. Dessa forma, mesmo que a ética discursiva objetive uma distribuição de encargos cognitivos mais equitativa do que a apresentada no Liberalismo Político, referido fardo permanece, pois a exigência de neutralidade no plano da justificação pública continua demandando uma separação cognitiva entre as visões religiosas e as exclusivamente políticas.

Em segundo lugar, como Rawls, ao contrário de Habermas, não estabelece as mesmas distinções entre deliberação e justificação na razão pública, as diferenças entre as duas abordagens são obscurecidas. Por um lado, parece bastante evidente que as restrições estabelecidas pelos deveres de civilidade e reciprocidade também estão presentes no princípio de neutralidade que Habermas introduz às bases de justificação da esfera pública formal. Nesse sentido, as exigências da razão pública e da esfera pública formal são muito próximas, senão coincidentes. Por outro lado, assim como faz a ética discursiva, o Liberalismo Político também reconhece os benefícios da multiplicidade de vozes no interior do ambiente social. Dessa forma, ainda que Rawls afaste o discurso religioso da razão pública (a qual afirma ser direcionada à justificação pública), também reconhece duas outras formas de deliberação pertencentes à visão ampla da cultura política.

São elas a declaração, correspondente ao discurso interno das doutrinas religiosas em si, e a conjectura, definida como o discurso externo que se aproxima da doutrina religiosa no esforço de demonstrar a sua compatibilidade com uma concepção política de justiça (RAWLS, 2005, p. 465-466). Assim, ao interpretar a razão pública como um ambiente de justificação, e a visão ampla da cultura política como uma extensão que incorpora elementos de deliberação variados, as visões de Habermas e Rawls tornam-se quase coincidentes (MAUTNER, 2013, p. 16-18.).

Não obstante as diferenças entre as construções formuladas pelos dois autores, o esforço comum em oferecer uma teoria de justiça adequada ao pluralismo razoável aproxima as concepções de cada um acerca das bases públicas de deliberação e justificação. Ambos parecem incorporar no ambiente deliberativo a multiplicidade de visões de mundo distintos, mas com a preocupação de restringir, no locus de justificação, elementos aceitáveis por toda a 
coletividade. Enquanto Rawls estabelece esta separação a partir de princípios substantivos de justiça, que o levam a conceber a razão pública de maneira mais restrita, contida nos valores autossustentados da justiça política, Habermas o faz através de uma teoria procedimentalista, sem determinar, a priori, restrições à esfera pública.

\section{CONCLUSÃO}

Pretendeu-se demonstrar, neste artigo, uma visão geral das posições de Rawls em Political Liberalism, e, em particular, a sua concepção acerca da razão pública e do espaço ocupado pelas doutrinas religiosas neste ambiente. Também pretendeu-se verificar o modo pelo qual algumas das objeções de Habermas ao projeto de Rawls levam-no a conceber a esfera pública de forma bastante diversa.

Destas colocações, conclui-se pela existência de fundamentos para afirmar que os projetos de ambos são diferentes, pois, enquanto Rawls sustenta a construção de uma teoria da justiça autossustentada e fundamentada por princípios subjetivos, Habermas elabora uma ética discursiva procedimental, que objetiva racionalizar os discursos públicos das diversas doutrinas existentes. No entanto, conclui-se, também, que essas distinções não alteram a preocupação dos autores em estabelecer bases públicas de justificação neutras, produzindo um tratamento bastante similar ao modo pelo qual concebem a atuação das doutrinas religiosas no ambiente político.

\section{REFERÊNCIAS BIBLIOGRÁFICAS}

FORST, R. The Right to Justification: Elements of a Constructivist Theory of Justice. Tradução de Jeffrey Flynn. Nova York: Columbia University Press, 2012.

GLEDHILL, J. Procedure in Substance and Substance in Procedure: Reframing the RawlsHabermas Debate. In: FINLAYSON, J. G.; FREYENHAGEN, F., (Eds.) Habermas and Rawls: disputing the political (Coleção Routledge studies in contemporary philosophy). Nova York: Routledge, 2011. p. 181-199. 
HABERMAS, J. Reconciliation Through the Public use of Reason: Remarks on John Rawls's Political Liberalism (Tradução de Ciaran Cronin). The Journal of Philosophy, v. 92, n. 3, p.109-131, 1995.

Religion in the Public Sphere. (Tradução de Jeremy Gaines). The European Journal of Philosophy, v.14, n.1, p.1-25, 2006.

MAUTNER, M. Religion in Politics: Rawls and Habermas on Deliberation and Justification. [Working paper]. Social Science Research Network. Disponível eletronicamente em: <http://ssrn.com/abstract=2164733>. Acesso em: 15 de junho de 2015.

FREEMAN, S. John Rawls: An Overview. In: . (Ed.). The Cambridge Companion

to Rawls (Coleção Cambridge Companions to Philosophy). Cambridge: Cambridge University Press, 2003, p. 347-367.

RAWLS, J. A Theory of Justice (Revised edition). Cambridge: Harvard University Press, 1999.

Political Liberalism (Expanded Edition). Nova York: Columbia University Press, 2005.

VIEIRA, Oscar Vilhena. A Moralidade da Constituição e os Limites da Empreitada Interpretativa, ou entre Beethoven e Bernstein. In: SILVA, Virgílio Afonso da (Org.). Interpretação Constitucional. São Paulo: Malheiros Editores, 2005, p. 217-254.

YATES, Melissa. Rawls and Habermas on religion in the public sphere. Philosophy \& Social Criticism, v. 33, n. 7, p.880-891, 2007. 